\title{
Effect of Hydroxyethylrutosides on Blood Oxygen Levels and Venous Insufficiency Symptoms in Varicose Veins
}

\author{
ANDREW J. McEWAN, COLIN S. MCARDLE
}

British Medical fournal, 1971, 2, 138-141

\section{Summary}

Oxygen levels (tension, saturation, and content) in blood from varicose leg veins were found to be significantly lower than those in blood from normal leg veins at the same site on the limb under the same laboratory conditions. Treatment with hydroxyethylrutosides significantly increased the oxygen levels in blood from varicose veins, and this was associated with an improvement in leg symptoms attributable to venous insufficiency. Hydroxyethylrutosides have been shown to have a beneficial effect on capillary dysfunction in venous stasis.

\section{Introduction}

Treatment of varicose veins by surgical measures or by sclerosing injections produces cosmetic improvement, healing of nutritional skin lesions, and relief from the symptoms of venous insufficiency. It has been reported that relief from these symptoms can also be obtained by treatment with hydroxyethylrutosides, an orally administered vasoactive substance.

Paroven, the product used, is a mixture mainly of mono-, di-, tri-, and tetra- $O-(\beta$-hydroxyethyl) rutosides containing not less than $45 \%$ troxerutin, the approved name of the principle compound tri-O-( $\beta$-hydroxyethyl) rutoside. Hydroxyethylrutosides have been reported to relieve leg symptoms associated with varicose veins (Fitzgerald, 1967; Allen, 1970; Rose, 1970) and to accelerate healing of varicose ulcers (Ghittoni and Martini, 1967). The precise mode of action of hydroxyethylrutosides when tissue microcirculation is embarrassed by venous stasis and venous hypertension is uncertain, but experimental studies indicated that its principal effect is on capillary and venule function and that it is not a vasodilator. Enhanced capillary resistance (Foelsche, 1968), reduced capillary permeability (Harrison, 1967), reduction of oedema (Fabre and Rudhardt, 1962), and augmented venous return (Pfister and Lindner, 1967) have been reported after administration of hydroxyethylrutosides. Swart (1970) observed an increased skin blood flow in the vicinity of varicose ulcers whose healing had been accelerated by hydroxyethylrutosides treatment.

If venous stasis, disturbance of perfusion, and hypoxia due to stagnation cause the symptoms and complications in varicose veins it should be possible to detect in varicose vein blood evidence of inadequate tissue blood flow and deranged metabolism. If symptomatic relief is due to amelioration of these microcirculatory and metabolic disorders evidence of improved tissue blood flow and oxygenation should be detectable in varicose vein blood after treatment with hydroxyethylrutosides. The following investigation was designed to study this possible effect of hydroxyethylrutosides.

Hyperbaric Unit, University Department of Surgery, Western Infirmary, Glasgow W.1

ANDREW J. MCEWAN, F.R.C.s. (ENG., GLASG.), Senior Surgical Registrar COLIN S. MCARDLE, F.R.C.S. (ENG., ED.), Registrar

\section{Methods}

Blood was taken from the leg veins of six normal male volunteers whose average age was 29 and from 14 male and female patients with varicose veins whose average age was 42 . All the patients had gross varicose veins in the long saphenous system, some showed evidence of impaired skin nutrition distally, and all complained of leg symptoms of venous insufficiency. Their varicose veins had been visible for an average of 12 years and troublesome symptoms present for an average of four years. They were otherwise healthy. The volunteers had neither signs nor symptoms of varicose veins.

Two separate blood samples were taken from the same leg vein in each individual. The venepunctures were made at a standard site below the knee on the anteromedial aspect of the upper third of the leg. The samples were withdrawn into heparinized syringes by a routine anaerobic technique, and blood gas estimations were made immediately. All the samples were taken between 10 and 11.30 a.m. and the environmental temperature varied between 20 and $22^{\circ} \mathrm{C}$. The subject sat for 10 to 15 minutes with the foot and leg exposed before the blood was taken from the dependent leg of the seated subject. With the volunteers there was an interval of one to six weeks between taking samples. With the first five patients the interval between taking samples was one to three weeks, and no treatment was given. The next nine patients were given Paroven $250 \mathrm{mg}$ four times a day for four weeks after taking the first sample and before the second sample was taken, each patient taking Paroven up to and including the second sampling day. There were no significant differences in the history, symptoms, and signs of the patients in the treated and untreated groups, and each contained males and females.

The measurements made from the venous blood were oxygen tension $\left(\mathrm{Po}_{2}\right)$, carbon dioxide tension $\left(\mathrm{PCO}_{2}\right), \mathrm{pH}$, haemoglobin, packed cell volume, and temperature. The blood gases were measured in a triple electrode system (Radiometer Micro Electrode type AME 1 with Oxygen Monitor type PMA 928) calibrated with gases of known concentration and solutions of known $\mathrm{pH}$. The differences in the measurement of oxygen tension in blood and gas (McDowall, Ledingham, and Tindal, 1968) were allowed for by calculating a correction factor, derived for each day's measurements, using blood tonometered with a known tension of oxygen in a rotating syringe (Torres, 1963). This blood-gas correction factor was applied to each of the measured $\mathrm{Po}_{2}$ values.

The venous blood temperature was determined by a needle thermocouple incorporated in the nozzle of a disposable plastic syringe which was substituted for the sampling syringe when this was removed, the venepuncture needle having been left in situ. The temperature was recorded by a universal electric thermometer (Ellab, type TE3). When blood was drawn at a steady rate into the plastic syringe the flow bathed the thermocouple and blood temperature was taken as the highest temperature recorded on the thermometer. This temperature was usually achieved after 3 to $5 \mathrm{ml}$ of blood had been withdrawn into the syringe.

The venous blood $\mathrm{Po}_{2}$ (blood-gas factor corrected), $\mathrm{Pco}_{2}$, and $\mathrm{pH}$ were corrected for the difference between the temperature of the blood and the temperature of the electrode recirculating system $\left(37^{\circ} \mathrm{C}\right)$ with the Radiometer Blood Gas 
Calculator (984-300). The latter was also used to calculate standard bicarbonate and base excess (both derived from $\mathrm{pH}$, $\mathrm{PCO}_{2}$, and haemoglobin) and oxygen saturation (derived from $\mathrm{pH}, \mathrm{Po}_{2}$, and base excess) for each venous blood sample.

The subsequent data were derived as follows: (1) Venous blood oxygen content $(\mathrm{ml} / 100 \mathrm{ml})=\mathrm{Hb}(\mathrm{g}) \times 1.34 \times$ $\frac{\% \text { Saturation }}{100}+\mathrm{Po}_{2}(\mathrm{~mm} \mathrm{Hg}) \times 0.0031$ (Bunsen coefficient). The value for blood oxygen content calculated in this way is no different from the value obtained by a direct measurement with the Van Slyke technique (Ledingham, McBride, Parratt, and Vance, 1970). (2) Arterial blood oxygen content was calculated from the above formula, an assumed value of $95 \mathrm{~mm}$ $\mathrm{Hg}$ for $\mathrm{Po}_{2}$ and $97 \%$ for oxygen saturation being used (Comroe, Dripps, Dumke, and Denning, 1945). (3) Tissue oxygen extraction $(\%)=100 \times$ arterial oxygen content $(\mathrm{ml} / 100 \mathrm{ml})$ minus venous oxygen content $(\mathrm{ml} / 100 \mathrm{ml}) \div$ arterial oxygen content $(\mathrm{ml} / 100 \mathrm{ml})$.

\section{Results}

The following results are the fully corrected venous blood gas values and the derived data calculated from them. The blood temperature correction was particularly important. The average temperature of blood from normal veins was $33 \cdot 1^{\circ} \mathrm{C}$ and from varicose veins $32.9^{\circ} \mathrm{C}$. No difference in temperature of varicose vein blood was observed after treatment with hydroxyethylrutosides.

Normal Volunteers.-The mean normal leg-vein blood values from the respective first and second samples were as follows: $\mathrm{Po}_{2}, 35 \cdot 2 \pm 3.4$ and $35.3 \pm 4.2 \mathrm{~mm} \mathrm{Hg}$ (Fig. 1); $\mathrm{PCO}_{2}$ $39.9 \pm 1.0$ and $39.4 \pm 1.4 \mathrm{~mm} \mathrm{Hg} ; \mathrm{pH}, 7.431 \pm 0.006$ and $7 \cdot 429 \pm 0.009$ units; oxygen saturation, $78.3 \pm 4.8$ and 77.9 $\pm 4.6 \%$; oxygen content, $17.3 \pm 1.2$ and $16.9 \pm 0.7 \mathrm{ml} / 100 \mathrm{ml}$ (Fig. 2); standard bicarbonate, $26.5 \pm 0.6$ and $26.1 \pm 0.7$ $\mathrm{mEq} / 1$; and base excess, $+2.2 \pm 0.8$ and $+1.8 \pm 0.7 \mathrm{mEq} / 1$. (Fig. 3). Tissue oxygen extraction at the time of the first and second samples was $20 \cdot 0 \pm 5 \cdot 0$ and $20 \cdot 3 \pm 4 \cdot 7 \%$ (Fig. 4). There was in these measurements no statistically significant difference between the first and second blood samples.

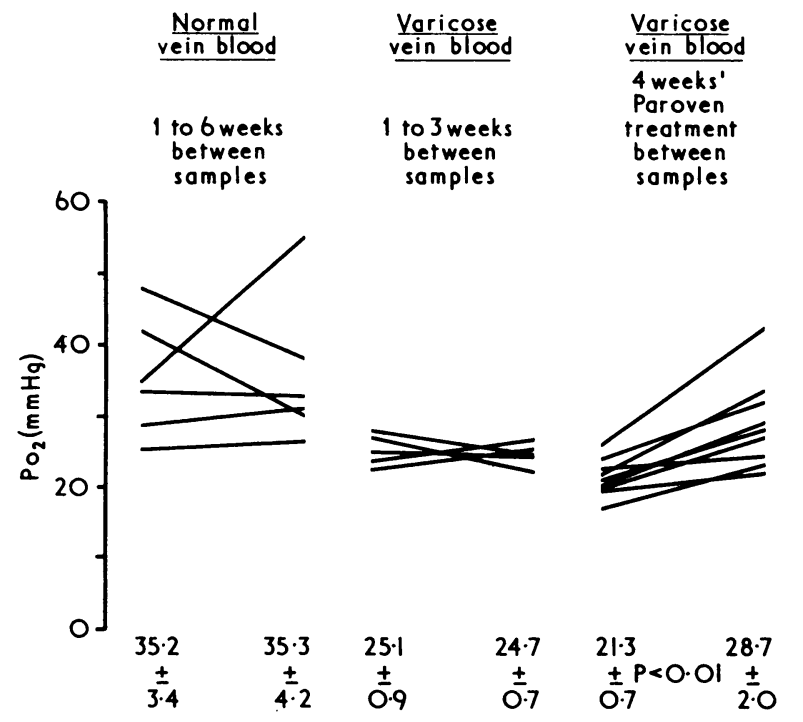

FIG. 1-Leg venous blood $\mathrm{Po}_{2}$ measured in two separate blood samples from the same vein, with means, standard errors, and significance of difference.

Untreated Patients.-The mean varicose leg-vein blood values from the respective first and second samples were as follows: $\mathrm{PO}_{2}, 25.1 \pm 0.9$ and $24.7 \pm 0.7 \mathrm{~mm} \mathrm{Hg}$ (Fig. 1);

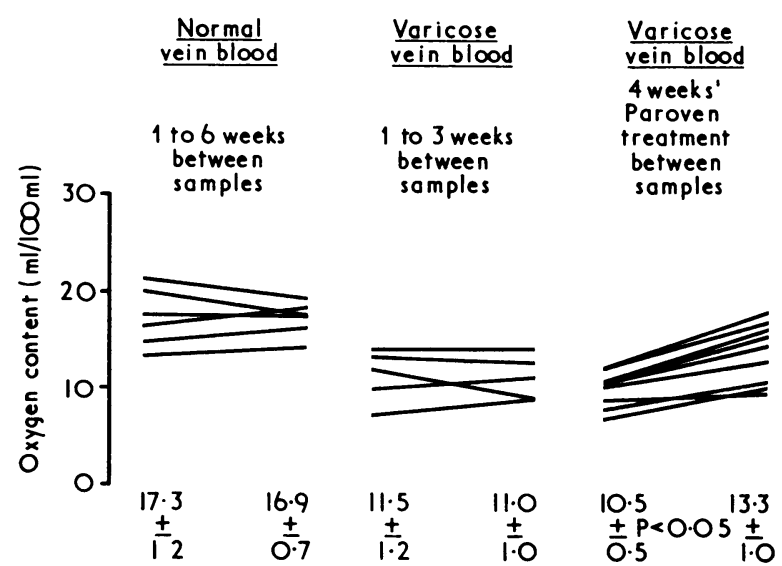

FIG. 2-Leg venous blood oxygen content measured in two separate blood samples from the same vein, with means, standard errors, and significance of difference.

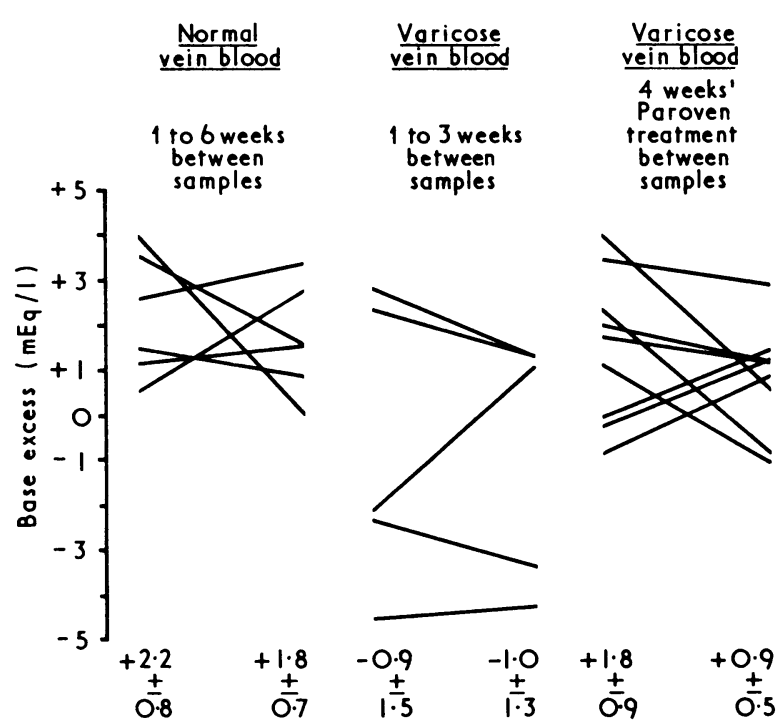

FIG. 3- Leg venous blood base excess measured in two separate blood samples from the same vein, with means and standard errors.

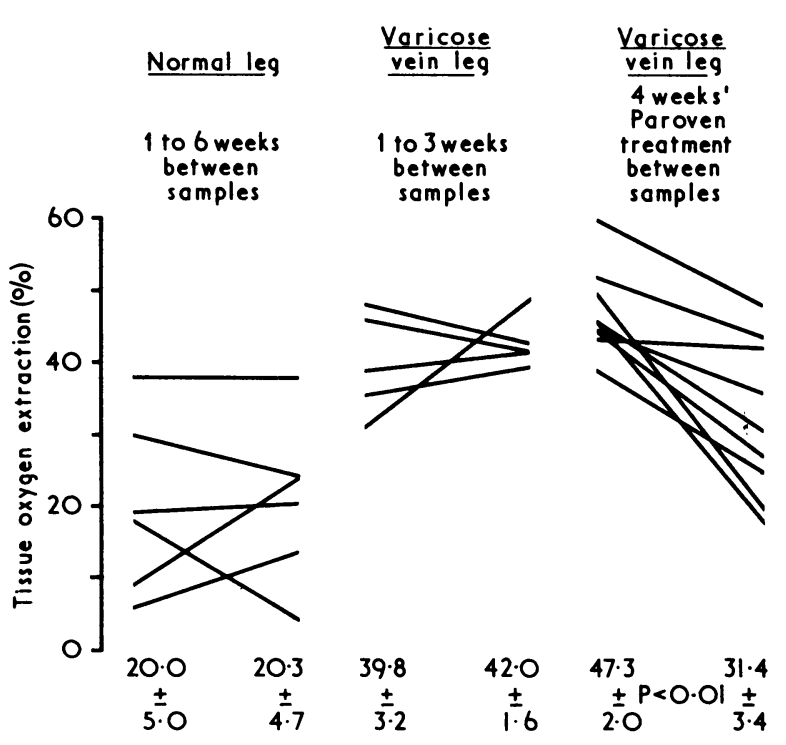

FIG. 4-Leg tissue oxygen extraction at the time of taking two separate venous blood samples, with means, standard errors, and significance of difference. 
$\mathrm{PCO}_{2}, 39.8 \pm 2.4$ and $43.1 \pm 2.3 \mathrm{~mm} \mathrm{Hg} ; \mathrm{pH}, 7.389 \pm 0.019$ and $7.365 \pm 0.006$ units; oxygen saturation, $59.0 \pm 3.3$ and $56.7 \pm 1.6 \%$; oxygen content, $11.5 \pm 1.2$ and $11.0 \pm 1.0 \mathrm{ml} /$ $100 \mathrm{ml}$ (Fig. 2); standard bicarbonate, $23.9 \pm 1.4$ and $23.6 \pm$ $1.1 \mathrm{mEq} / 1$; and base excess, $-0.9 \pm 1.5$ and $-1.0 \pm 1.3$ $\mathrm{mEq} / 1$. (Fig. 3). Tissue oxygen extraction at the time of the first and second samples was $39.8 \pm 3 \cdot 2$ and $42.0 \pm 1.6 \%$ (Fig. 4). There was in these measurements no statistically significant difference between the first and second blood samples.

Paroven-treated Patients.-The mean varicose leg-vein blood values from the respective first and second samples were as follows: $\mathrm{PO}_{2}, 21.3 \pm 0.7$ and $28.7 \pm 2.0 \mathrm{~mm} \mathrm{Hg}$ (Fig. 1); $\mathrm{PCO}_{2}, 39.1 \pm 1.8$ and $40.0 \pm 1.6 \mathrm{~mm} \mathrm{Hg} ; \mathrm{pH}, 7.433 \pm$ 0.015 and $7.414 \pm 0.010$ units; oxygen saturation, $51.8 \pm 1.9$ and $67.6 \pm 3.7 \%$; oxygen content, $10.5 \pm 0.5$ and $13.3 \pm 1.0$ $\mathrm{ml} / 100 \mathrm{ml}$ (Fig. 2); standard bicarbonate, $26.0 \pm 0.7$ and $25.3 \pm 0.4 \mathrm{mEq} / 1$; and base excess, $+1.8 \pm 0.9$ and +0.9 $\pm 0.5 \mathrm{mEq} / \mathrm{l}$. (Fig. 3). Tissue oxygen extraction at the time of the first and second samples was $47 \cdot 3 \pm 2 \cdot 0$ and $31 \cdot 4 \pm$ $3.4 \%$ (Fig. 4). There was a statistically significant difference between the first and second blood samples with respect to the mean values for $\mathrm{Po}_{2}(\mathrm{P}<0.01)$, oxygen saturation $(\mathrm{P}<0.01)$, and oxygen content $(\mathrm{P}<0.05)$ but not for $\mathrm{PCO}_{2}, \mathrm{pH}$, standard bicarbonate, and base excess. Between the times of the first and second samples there was a statistically significant difference in tissue oxygen extraction $(P<0.01)$.

Analysis of the results of the measurements made on the initial blood samples from the six normal leg veins and from the 14 varicose leg veins showed that in varicose vein blood the $\mathrm{Po}_{2}(23.2 \pm 0.8 \mathrm{~mm} \mathrm{Hg})$ was lower $(\mathrm{P}<0.01)$ than normal $(35.2 \pm 3.4 \mathrm{~mm} \mathrm{Hg})$, oxygen saturation $(55.4 \pm 2.6 \%)$ was lower $(P<0.001)$ than normal $(78.3 \pm 4.8 \%)$, and oxygen content $(11.0 \pm 0.9 \mathrm{ml} / 100 \mathrm{ml})$ was lower $(P<0.001)$ than nor$\mathrm{mal}(17 \cdot 3 \pm 1.2 \mathrm{ml} / 100 \mathrm{ml})$. Oxygen extraction $(43.6 \pm 2.6 \%)$ in the tisues of varicose vein legs was higher $(\mathrm{P}<0.001)$ than normal $(20.0 \pm 5.0 \%)$. There were no significant differences in the other measurements.

The leg symptoms of venous insufficiency in the patients were throbbing, aching, tingling, cramps, itch associated with eczema, heaviness, burning, and in some instances pain. The symptoms were generally worst in the evening, particularly if there had been prolonged standing or walking. Seven out of nine patients reported an improvement in leg discomfort after treatment with Paroven. It usually began during the second week of treatment, and one patient claimed complete relief. The only patient with a varicose ulcer reported complete healing in the third week of treatment. There was also a concurrent 10-day treatment with a Viscopaste bandage, but the ulcer was over $3 \mathrm{~cm}$ in diameter, had been present for three years, and had previously resisted treatment. Another patient claimed relief from oedema of the ankle.

There were no troublesome side effects of treatment with Paroven, but one patient reported a single episode of unaccustomed abdominal discomfort and diarrhoea. One of the two patients who reported no improvement with treatment experienced a feeling of tightness in the calf during the first week of treatment.

\section{Discussion}

No difficulty was encountered in finding a suitable varicose vein for venepuncture, and in every patient bar one the second blood sample was taken from exactly the same vein from which the first sample had been taken. Normal veins at the selected site are invariably invisible and of ten impalpable, and some prospective normal volunteers had to be rejected because of failure to locate venous blood. Tourniquets were not used, and in some of the volunteers it was impossible to say if the second blood sample came from exactly the same vein as did the first.
The venous blood gases, oxygen saturation and oxygen content, and the indices of non-respiratory acid-base metabolism (stàndard bicarbonate and base excess) were measured or calculated by routine laboratory techniques. The use of an assumed arterial value in calculating oxygen extraction seemed permissible, since none of the patients or volunteers had a history of chronic respiratory disorders and all could reasonably be expected to have good respiratory function and normal arterial blood oxygenation. In view of the standard conditions of the study, the term "leg-tissue oxygen extraction" was believed to relate to an approximately similar block of leg tissue in both volunteers and patients.

DeTakats, Quint, Tillotson, and Crittenden (1929) reported a low varicose vein blood oxygen content. Pinlachs and VidalBarraquer (1953) and Fontaine (1957) suggested pathological arteriovenous shunting of blood as the primary cause of venous overîlling leading to secondary vein lesions. At tissue level a state of anaemic rather than stagnant annoxia could therefore exist, and in support of their theory they reported a high varicose vein blood oxygen tension and content. Rivoire, Jaccoud, Golden, and Horn (1970) seem to have confirmed this. Ryan (1970) drew attention to observations that secm to show that venous stasis itself can cause diversion of the tissue blood flow through normally insignificant, alternative channels.

This investigation was not designed to resolve the controversy about the aetiology of varicose veins, but it was necessary to review previously reported contradictory findings on varicose vein blood oxygenation. These were difficult to assess and compare on account of the following differences in method or absence of information in the reports: position of the leg and state of rest of the subject, site on the leg from which varicose vein blood samples were taken, comparison of apparently abnormal varicose vein blood oxygen tension and content values with supposedly normal values from venous blood taken from either the subject's clinically unaffected other leg or the subject's arm or a normal subject's leg, and comparison by average difference rather than by statistical evalution. The oxygenation of venous blood is related to metabolic activity and blood flow, and the amount of blood in a varicose vein and the intravenous pressure vary with activity and change of position from erect to recumbent. These factors alone could account for differences in varicose vein blood oxygenation and they must be standardized and stated before any meaningful interpretation of results or comparison of results can be made.

Under the standardized conditions of this investigation the mean values of the criteria used to define the oxygenation and acid-base state of blood from normal leg veins and from varicose leg veins were stable and reproducible. Blood from varicose veins had a significantly lower than normal $\mathrm{Po}_{2}$, oxygen saturation, and oxygen content, and the oxygen extraction in the tissues of the varicose vein legs was higher than normal. These figures were what could be expected in tissue blood flow stagnation and when the oxygen taken from the blood was greater than normal to compensate the abnormally slow flow. The similarity between $\mathrm{PCO}_{2}$ and $\mathrm{pH}$ in blood from normal veins and varicose veins may seem surprising when a tissue blood flow insufficiency is postulated in the varicose vein legs. However, levels of $\mathrm{PCO}_{2}$ and $\mathrm{pH}$ in peripheral venous blood are determined not primarily by blood flow but by tissue metabolism. An increased oxygen extraction from a decreased blood flow can still maintain aerobic metabolism without acidosis developing.

McEwan, Stalker, and Ledingham (1970) showed that tissues in a foot with a normal arterial blood flow can reduce their level of metabolism as the blood flow in the foot falls with vasoconstriction. Within limits peripheral tissues can probably adjust their metabolism to the prevailing blood flow. An autoregulatory lowering of the level of metabolism in the tissues of varicose vein legs may therefore have occurred 
in response to the slower than normal tissue blood flow. The normal values for standard bicarbonate and base excess in varicose vein blood indicate the absence of any significant tissue metabolic acidosis and support the above interpretation of the results.

Treatment with Paroven significantly altered the $\mathrm{Po}_{2}$, oxygen saturation, and the oxygen content of varicose vein blood and the oxygen extraction in tissues of varicose vein legs towards normal values. The improved venous blood oxygenation and the reduced tissue oxygen extraction indicated better tissue perfusion with less blood oxygen having been taken from the increased capillary blood flow. The unchanged venous blood metabolic acid-base values probably implied some upwards adjustment in the level of tissue metabolism, since an unchanged tissue metabolism and an increased blood flow would have resulted in a fall in $\mathrm{PCO}_{2}$ and a rise in $\mathrm{pH}$ in venous blood, and this was not observed.

There was an interesting relationship between symptomatic improvement and objective measurements recorded after treatment with Paroven. The seven patients who reported symptomatic relief had an average increase in varicose vein blood $\mathrm{PO}_{2}$ of $8.1 \mathrm{~mm} \mathrm{Hg}$ and the two patients who experienced no symptomatic relief had an average increase in varicose vein blood $\mathrm{PO}_{2}$ of only $4.8 \mathrm{~mm} \mathrm{Hg}$. The proof of a direct correlation between blood gas changes and symptomatic improvement would require a double-blind trial of Paroven and was outside the scope of this study.

Tissue hypoxia, in the sense that oxygen supply was insufficient for the prevailing level of metabolism, did not seem to be present in legs affected by varicose veins. There was, however, good evidence to support the view that capillary blood flow or tissue perfusion was below the normal optimum level. A four-week course of Paroven seemed to have signifi- cantly improved tissue perfusion and oxygenation by its known vasoactive effect. This was accompanied by the previously recorded amelioration of the symptoms attributed to venous insufficiency. In the apparent absence of tissue hypoxia and acidosis these symptoms would therefore seem to have been due simply to extracellular fluid accumulation and venule and capillary distension.

Supplies of Paroven and details of previous investigations of the action and effect of $O$-( $\beta$-hydroxyethyl) rutosides were made available by Dr. A. David, Zyma (United Kingdom) Limited.

\section{References}

Allen, S. (1970). Practitioner, 205, 221.

Comroe, J. H., Dripps, R. D., Dumke, P. R., and Denning, M. (1945). Fournal of the American Medical Association, 128, 710.

DeTakats, G., Quint, H., Tillotson, B. I., and Crittenden, P. J. (1929) Archives of Surgery, 18, 671.

Fabre, J., and Rudhardt, M. (1962). Médecine et Hygiène, 20, 161.

Fitzgerald, D. E. (1967). Practitioner, 198, 406.

Foelsche, W. (1968). Fortschritte der Medizin, 86, 273.

Fontaine, R. (1957). Surgery, 41, 6.

Ghittoni, S., and Martini, P. (1967). Anthologica Medica Santoriana, 81, 1. Harrison, R. G. (1967). British fournal of Dermatology, 79, 9.

Ledingham, I. McA., McBride, T. I., Parratt, J. R., and Vance, J. P. (1970). Fournal of Physiology, 210, 87.

McDowall, D. G., Ledingham, I. McA., and Tindal, S. A. P. (1968). Fournal of Applied Physiology, 24,324.

McEwan, A. J., Stalker, C. G., and Ledingham, I. McA. (1970). British Medical fournal 3,612 .

Pfister, R., and Lindner, U. (1967). Therapiewoche, 17, 674

Pfister, R., and Lindner, U. (1967). Therapiewoche, 17, 674.

Pinlachs, P., and Vidal-Barraquer, F. (1953). Angiology, 4, 59. Médecine de Lyon, $\mathbf{5 1}, 1180,501$.

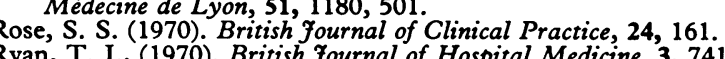

Ryan, T. J., (1970). British fournal of Hospital Medicine, 3, 741.

Swart, E. (1970). Unpublished results.

Torres, G. E. (1963). Fournal of Applied Physiology, 18, 1008.

\title{
Contact Dermatitis from Penetration of Rubber Gloves by Acrylic Monomer
}

\author{
J. S. PEGUM, F. A. MEDHURST
}

British Medical fournal, 1971, 2, 141-143

\section{Summary}

An orthopaedic surgeon developed dermatitis from acrylic materials. The acrylic monomer was found to penetrate surgical rubber gloves readily. Cases of "rubber glove dermatitis" with negative patch tests may have a similar explanation. Laboratory tests suggest that monomer does not damage rubber sufficiently to allow bacteria to penetrate gloves, but it remains possible that this would happen under theatre conditions.

\section{Case History}

An orthopaedic surgeon developed a rash on the hands in January 1970. A number of years previously he had had a rash of the hands

\section{London Hospital, London E1 1BB}

J. S. PEGUM, M.D., F.R.C.P., Physician to Skin Department, London Hospital Medical College, London E1 1BB

F. A. MEDHURST, PH.D., Lecturer in Bacteriology attributed to the use of disposable rubber gloves. This had resolved when solution gloves were substituted. Examination showed redness and scaling of the palm, the palmar surface of the fingers, and the finger-webs of the left hand. The tops of the right index and little fingers were similarly affected. The rash was improved by steroid ointment but tended to relapse within an hour of the finish of operating sessions.

Patch tests to the gloves, the glove powder, and the other obvious things related to operating procedures were negative. When operating on the hip he used acrylic cement to secure a plastic acetabulum and a stainless steel prosthetic substitute for the head of the femur. He moulded the cement in the left palm and then rammed the mass into the acetabulum and into the cavity of the femur, using the tip of the right index finger and the tip of the right little finger. These were exactly the areas affected. Though it seemed unlikely that the cement would penetrate intact rubber gloves, patch tests were done and proved strongly positive. Tests in which the acrylic monomer was enclosed in the sealed finger of a rubber glove were also positive. An in-vitro test recorded below confirmed that monomer rapidly penetrated intact rubber gloves. The surgeon then took care not to handle the bone cement and the hands gradually improved. On one occasion, however, he forgot his hypersensitivity and used the cement. This was followed by a rapid relapse. The skin settled again and when last seen (November 1970) the hands were quite normal apart from slight scaling and redness of the tip of the left index finger. 